\title{
Making a Derivative Radon-Risk Map of Williamsburg, Virginia
}

Dorian V. Miller, C.R. Berquist Jr., Alton L. Hipps, James M. Kaste, Zoey Mondshine, R. Heather Macdonald Department of Geology, William \& Mary, Williamsburg, VA 23187

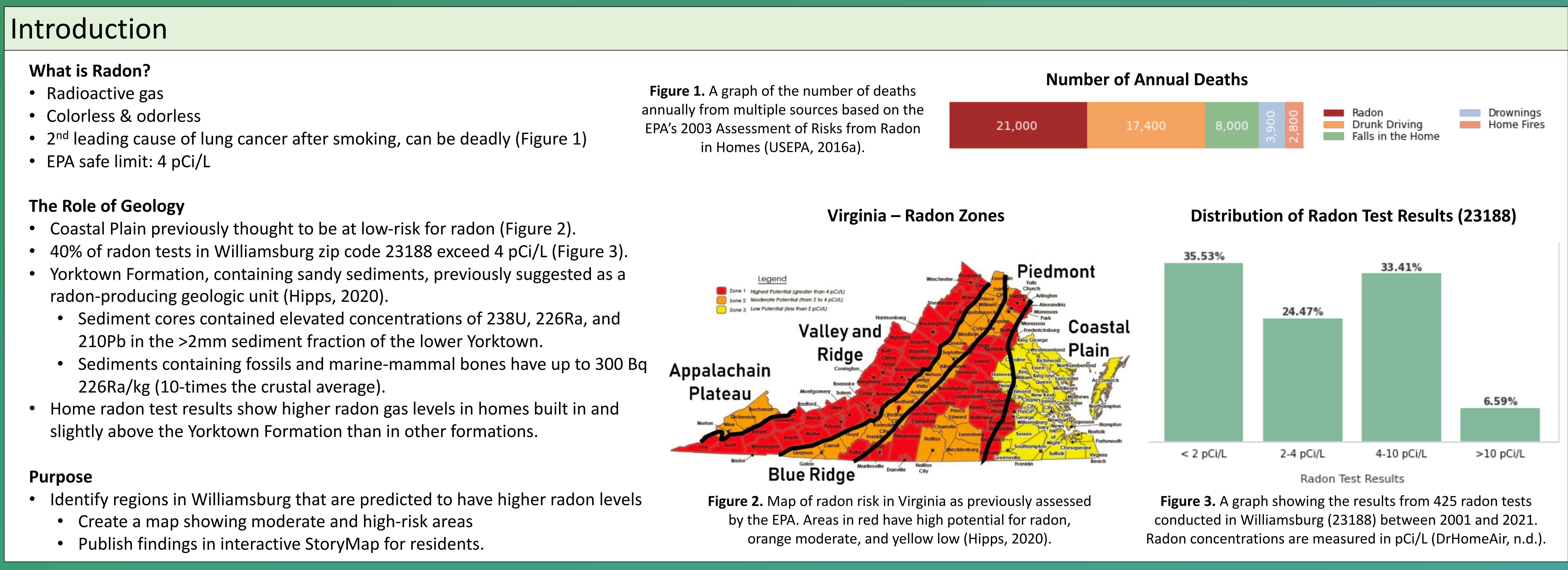

Methods

Datasets Used

- Topographic data (2-foot contour intervals)

- Building footprints

- Infrastructure GIS data from the City of Williamsburg

Method

Determined the top of the Yorktown Formation to be $58 \mathrm{ft}$ above sea level using field observations, borehole data

and the 1:24,000-scale geologic map of Williamsburg (Bick and Coch, 1969).

Areas below $58 f t$ were mapped as high risk.

Areas between $58 \mathrm{ft}$ and $64 \mathrm{ft}$ were mapped as moderate risk.

Created polygons using the contour data that delineated each of these risk areas.

Clipped polygons to the extent of the Williamsburg city limits.

- The fin map (Figure 4) is embedded in an interactive ArcGIS StoryMap that allows residents to input their address effects.

A William \& Mary geology major is currently conducting tests

Continue to monitor radon trends in the region

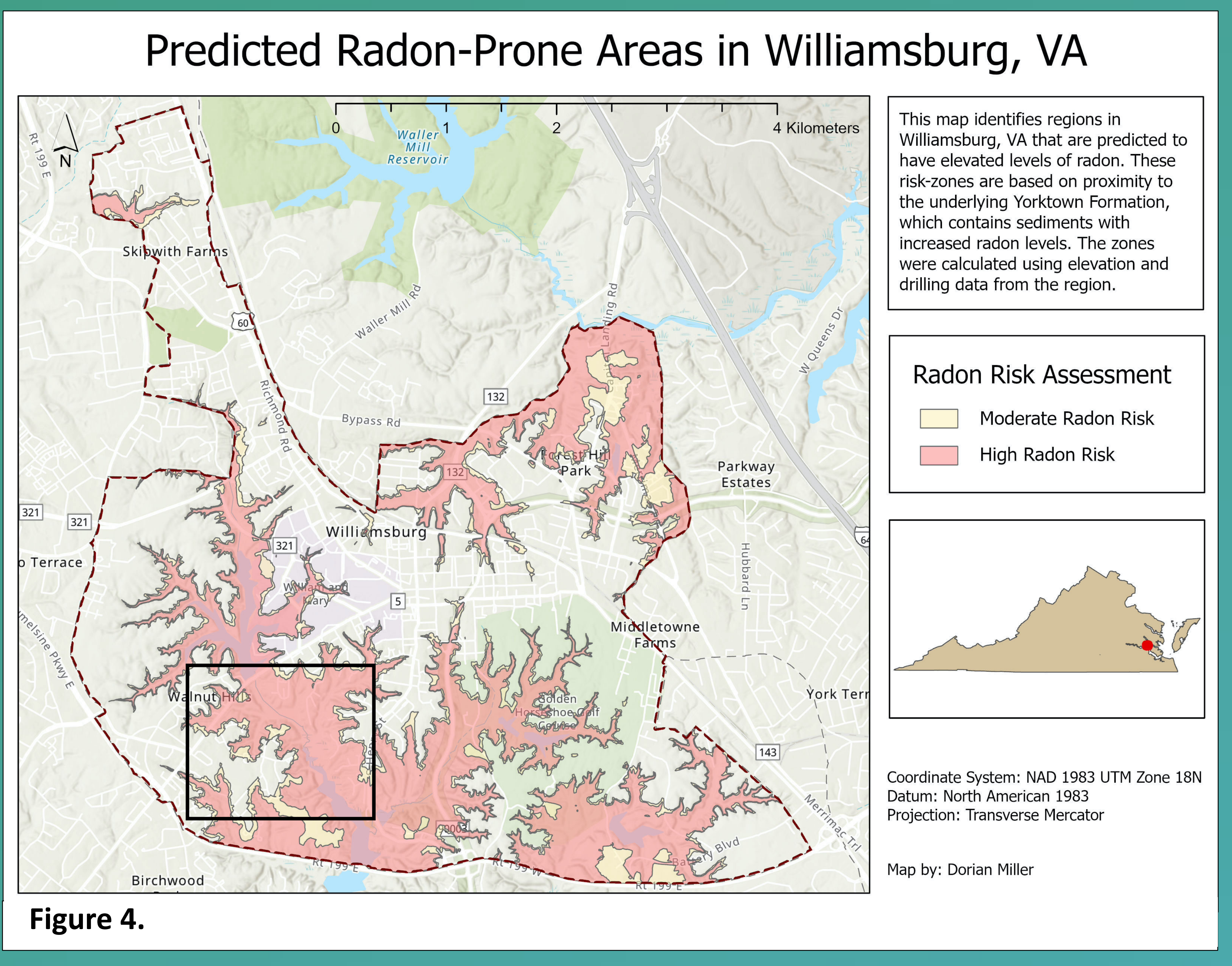

Results
- Creation of radon risk map derived from geology (Figure 4)
Identified the number of homes within each risk area

- Hentip homeowners determine whether they could be at risk - The overlap between development and predicted risk helps
identify areas that have the highest health hazard (Figure 5).

Validation

to determine the validity of the map.

Next Steps

Publish StoryMap for residents of Williamsburg to view and

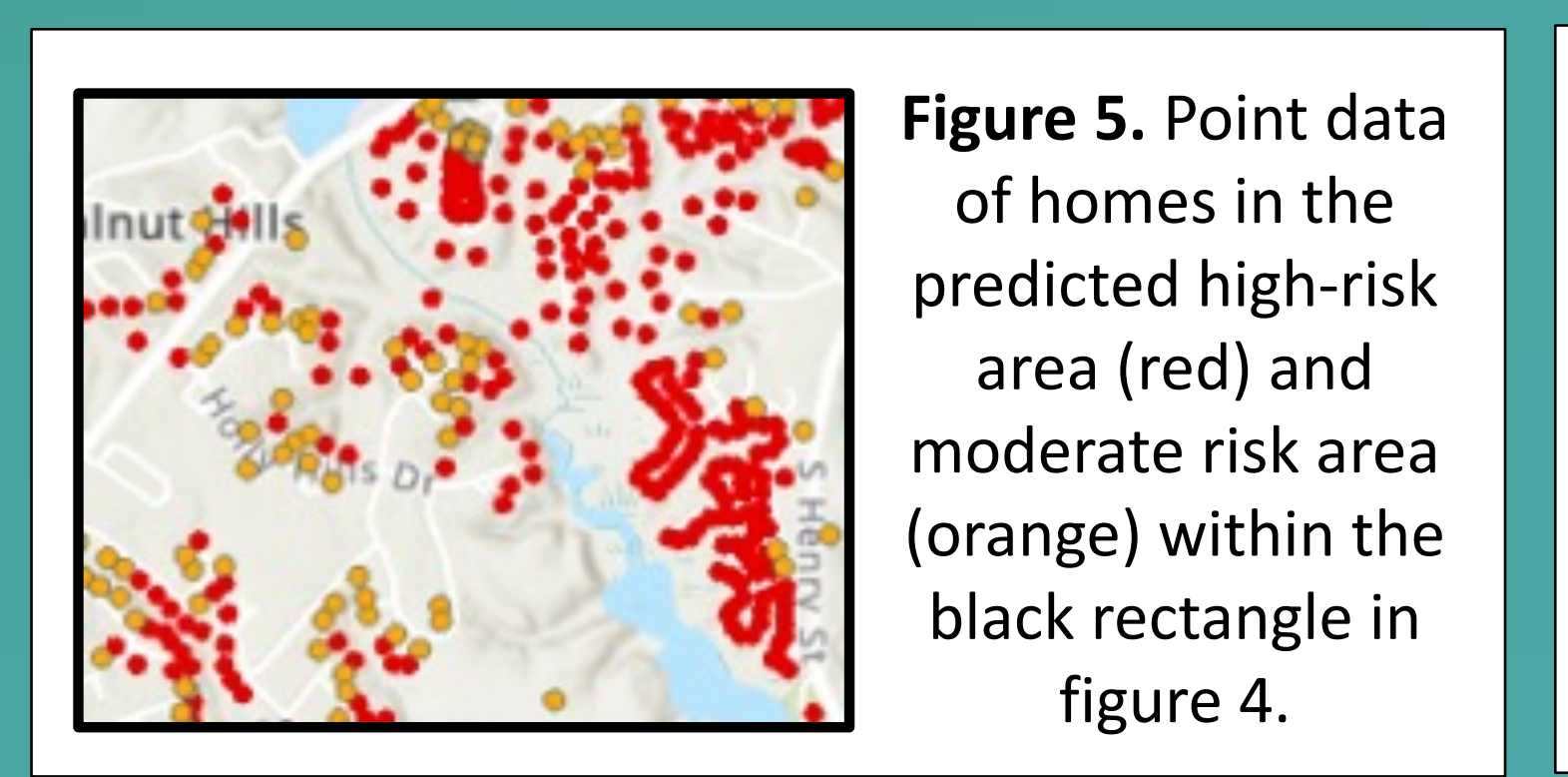

Interactive StoryMap

can this QR code to visit the

interactive StoryMap that can

used to explore radon risk
levels in Williamsburg.

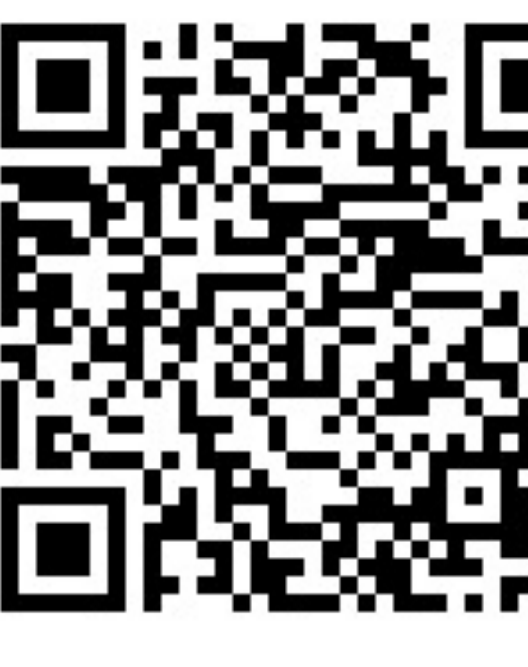

References

Bick, K.F., and Coch, N.K. Geology of the Williamsburg, Hog Island, and Bacons Castle Quadrangles, Virginia: Report of Investigations

Plate 1 p., https://www.dmme.virginia.gov/commercedocs/R__18.pdf (accessed March 2021).

check Results in Your Area DrHomeAir, https://www.doctorhomeair.com/check-results-in-area/ / (accessed March 2021).

Hipps, A., 2020, High Localized Uranium and 226Ra in the Mid-Atantic Coastal Plain: Implications for Radon Hazards: William \& Mary

USEPA, 2016a, A Aitizen's Guidd to Radon:, http://www.epa.gov/radon/pubs/citguide.html (accessed October 2019. 